

v. 10, n. 19,2021

\title{
RELATÓRIOS DE AUDITORIA: FREQUÊNCIA DA ALTERAÇÃO DAS OPINIÕES DOS AUDITORES NO SEGMENTO TRADICIONAL BOVESPA DA B3
}

\section{AUDIT REPORTS: FREQUENCY OF CHANGED AUDITOR'S OPINIONS IN THE B3 TRADITIONAL SEGMENT BOVESPA}

\author{
Nome: Ernando Fagundes \\ Instituição: Universidade Federal de Santa Catarina (UFSC) \\ Faculdade de Tecnologia Nova Palhoça (FATENP) \\ E-mail: fagundes.ernando@gmail.com \\ Nome: Jéssica Pereira \\ Instituição: Faculdade de Tecnologia Nova Palhoça (FATENP) \\ E-mail: jessica@eldoradocontabilidade.net.br
}

\section{RESUMO}

Este estudo teve por objetivo verificar as opiniões emitidas nos relatórios de auditores independentes de empresas listadas no Brasil, Bolsa e Balcão (B3). Para isto, analisou-se 179 companhias enquadradas em variados setores e classificadas no segmento Tradicional Bovespa dos anos de 2017 e 2018. Observou-se que os tipos de opiniões apresentadas nos relatórios pelos auditores foram, sem ressalva, com ressalva e abstenção de opinião, inexiste relatórios com a opinião do tipo adversa. Os dados apresentaram que 165 companhias receberam o relatório sem ressalva em 2017 e este número caiu 3,03\% em 2018 (160), o que aumentou os relatórios emitidos com opinião modificada. Grande parte dos motivos que acarretam o relatório ser emitido com opinião modificada se repetem nos anos. No último ano apresentaram motivos que valem sem ressaltados, como consequências da operação Lava Jato no Brasil.

Palavras-chave: Auditoria. Relatório de auditoria. Opinião do auditor.

\section{ABSTRACT}

This study aimed to verify the opinions expressed in the reports of independent auditors of companies listed in Brazil, Bolsa and Balcão (B3). For this, analyze 179 companies classified in various sectors and classified in the traditional Bovespa segment of 2017 and 2018. This is a quantitative and documentary research. It was identified as opinions expressed in the reports and reasons that led the auditors to issue modified opinions. The types of opinions allowed in the auditors' reports were, without exception, with the exception and abstention of opinion, nonexistent reports with an adverse type of opinion. Data reported from 165 companies that received reports without exception in 2017 and that number fell 3.03\% in 2018 (160), which increased the reports issued with modified opinion. There was a $33.33 \%$ increase in the presentation of modified opinions in 2018 compared with 2017. Most of the reasons that lead, or report being issued with modified opinion if repeated in years. Last year, the reasons why the Lava Jato operation in Brazil did not occur.

Keywords: Audit. Audit Report. Auditor's opinion. 


\section{Revista \\ UNEMAT de \\ Contabilidade}

v. 10, n. 19,2021

\section{INTRODUÇÃO}

Organizações que buscam crescimento podem necessitar de recursos de terceiros para impulsionar o seu desenvolvimento. Para isso, abrem seu capital a novos acionistas tornando-as (S/A). Caminho este para atrair investidores que contribuam na evolução de seus produtos ou serviços. Por conseguinte, essas organizações se obrigam a auditoria contábil (ALMEIDA, 2012), com base na Lei ${ }^{\circ} 6.404$ de 1976.

Ainda em 1976, a Lei $n^{\circ} .6 .385$ criou a Comissão de Valores Mobiliária (CVM), que define em seu art. 26: O auditor independente ou a empresa de auditoria somente poderá emitir relatórios de auditorias para S/A após obter seu registro na CVM (BRASIL, 1976).

O mercado financeiro torna-se mais transparente com os trabalhos da auditoria independente, que promove o exame dos relatórios financeiros, e expressa de forma clara e realista a posição financeira e patrimonial da companhia, isso previne conflitos entre os usuários desta informação e eleva a confiabilidade dos usuários ou futuros investidores na companhia (NASCIMENTO, 2018).

Os usuários da informação exigem das Companhias mais credibilidade e confiabilidade, pois, somente com informações reais serão capazes de tomar decisões eficientes (ASSIS, ALVARENGA, LACERDA, 2014). Outro quesito que a auditoria proporcionou foi a validade das demonstrações contábeis. Sem a devida avaliação de uma auditoria estas perdem sua validade (CVM, 2019).

A partir disto, nota-se um grande trabalho do auditor no setor público com interação com a iniciativa do setor privado nas operações da lavo jato ocorridas no Brasil recentemente (SANT'ANNA, 2018).

Assim como a criação da classificação da governança corporativa, que é o conjunto de práticas que tem por objetivo potencializar o desempenho de uma companhia ao defender todas as partes envolvidas, permite aos investidores o alcance ao capital (CVM, 2019).

As vantagens da auditoria contábil abrangem a administração da companhia (por apontar falhas no controle interno), os investidores e titulares do capital (por verificar a veracidade das informações patrimoniais e financeiras da companhia), o Fisco (pela maior exatidão das demonstrações contábeis), e por fim, a sociedade (ao transmitir mais confiabilidade) (CRC-CE, 2019). 


\section{Revista \\ UNEMAT de Contabilidade}

v. 10, n. 19,2021

Diante da relevância da opinião do auditor, como apontado. E, sabendo da possibilidade de modificação das opiniões por parte destes. Têm-se como pergunta de pesquisa: Qual a frequência das opiniões modificadas e não modificadas nos relatórios emitidos por auditorias independentes? Logo, objetiva-se verificar as opiniões emitidas nos relatórios de auditores independentes de empresas listadas na B3. Complementarmente, este estudo evidência os motivos apresentados para as opiniões modificadas dos tipos com ressalva, adversa e abstenção de opinião. Para isto, levantaram-se as opiniões nos relatórios de auditoria independente de 179 companhias listadas na B3, segmentadas pelo Tradicional Bovespa, dos anos de 2017 e 2018.

A contribuição deste trabalho para organizações empresariais, estudantes e para a sociedade é de demonstrar o quanto é útil o trabalho do auditor independente aos usuários das informações, o qual eleva o grau de confiabilidade das demonstrações contábeis, resultado de um trabalho que é resumido por meio de sua opinião. Apresentar os resultados da coleta de dados das informações publicadas com a frequência das opiniões emitidas, de forma clara para que possa servir de suporte para futuros pesquisadores, a fim de contribuir com o levantamento de informações aos usuários do resultado dos serviços prestados pelos auditores.

Este trabalho está organizado, além desta seção introdutória, da seguinte forma: a próxima seção trata sobre a fundamentação teórica do assunto pesquisado, na Seção 3 apresentam-se os procedimentos metodológicos aplicados, em seguida têm-se a análise e a discussão de resultados. Para finalizar, as considerações finais seguida das referências.

\section{FUNDAMENTAÇÃO TEÓRICA}

Trata-se nesta seção, os temas de governança corporativa e relatórios de auditoria independente, que abrangem assuntos relacionados à auditoria independente, relatório de auditoria, riscos de auditoria e tipos de opinião do auditor. Seguido dos trabalhos similares que servirão como base para o assunto aqui abordado com o levantamento de itens comparativos entre si. 


\section{Revista

\subsection{GOVERNANÇA CORPORATIVA}

Governança corporativa é o sistema pela qual as empresas e demais organizações são dirigidas, monitoradas e incentivadas, que envolve os relacionamentos entre sócios, conselho da administração, diretoria, órgãos de fiscalização, controle e demais partes interessadas (IBGC, 2019).

O Instituto Brasileiro de Governança Corporativa (IBGC) lançou em 1999 o seu primeiro Código das Melhores Práticas de Governança Corporativa. O objetivo de sua criação é para prevenir conflitos que ocorria entre proprietários e sócios. O instituto faz com que o comportamento dos administradores esteja de acordo com o que é melhor para a empresa. Segundo o código, a boa governança proporciona aos proprietários segurança sobre a gestão estratégica da empresa e a monitoração da direção executiva (IBGC, 2019).

Foram criados quatro princípios básicos da governança corporativa apresentados no Quadro 1 (IBGC, 2019).

QUADRO 1 - Princípios básicos da Governança Corporativa

\begin{tabular}{|l|l|}
\hline Princípios & Objetivos \\
\hline Transparência & $\begin{array}{l}\text { Demonstrar informações importantes aos seus usuários não só as } \\
\text { obrigadas por leis }\end{array}$ \\
\hline Equidade & Equilibrar o tratamento justo a todos os sócios e possíveis investidores \\
\hline Prestação de contas & Apresentar a sua atuação de forma clara \\
\hline Responsabilidade Corporativa & Manter zelo pela vida da organização \\
\hline
\end{tabular}

Fonte: Elaborado pelos autores (2019)

A B3 criou níveis de governança para as empresas aderirem voluntariamente ao segmento que desejar. Há alguns níveis chamados de diferenciados, sendo o Novo Mercado, Nível 1 e Nível 2, Bovespa Mais e Bovespa Mais Nível 2. De acordo com a B3 (2019), tais segmentos foram criados ao se perceber que para o desenvolvimento do mercado de capitais brasileiro, se faziam necessários segmentos adequados aos diferentes perfis das empresas.

A CMV exige por meio da Instrução Normativa ${ }^{\circ} 586$, que as companhias de capital de aberto terão que divulgar as informações sobre a aplicação das práticas da governança corporativa, titulado como "pratique e explique", deverá ser apresentado em até sete meses após o encerramento do exercício (CVM, 2017). 


\section{Revista \\ UNEMAT de Contabilidade}

v. 10, n. 19,2021

Esses segmentos diferenciados seguem regras além das exigidas por lei, que reforça o direito dos investidores por meio de um código de boas práticas mais rígidas a se seguir. Os segmentos não diferenciados designados como básicos, seguem o que é exigido por lei, e é facultado a seguir certas regras de governança como por exemplo ter reunião pública anual ou auditoria interna. $\mathrm{O}$ segmento de estudo desta pesquisa, o Tradicional Bovespa está enquadrado como nível básico (B3, 2019).

\subsection{RELATÓRIOS DE AUDITORIA}

Existem dois tipos de auditoria, interna e independente (externa). Esta pesquisa está relacionada com os relatórios de auditoria independente. Este tipo de auditoria exige que o auditor não tenha vínculo com a companhia auditada, para que sua opinião não seja afetada (BRASIL, 2016).

A Instrução Normativa n 308 de 1999, trata, sobre a rotatividade das auditorias, como um meio de prevenir a criação de ligações pessoais, em que só poderão prestar serviços para o mesmo cliente por cinco anos consecutivos e deve obedecer a um intervalo de no mínimo três anos para sua recontratação.

A base de estudo para o auditor elaborar o seu relatório de auditoria são as demonstrações contábeis que conforme a Lei das S/A ${ }^{\circ}$. 6.404/76 art. 176, deverão ser publicadas o balanço patrimonial, a demonstração de lucros e prejuízos acumulados, do resultado do exercício, fluxo de caixa, do valor adicionado e as notas explicativas. Além das demonstrações contábeis, o auditor faz o uso de informações complementares para a realização de seus exames em documentos, livros contábeis, registros e confirmações de informações com fontes externas (CRC-CE, 2019).

O produto do auditor é o seu relatório. Este segue um padrão básico, que deve conter: título, destinatário, opinião do auditor, base para opinião, continuidade operacional se aplicável, principais assuntos de auditoria, responsabilidade pelas demonstrações contábeis, responsabilidade do auditor independente pela auditoria das demonstrações contábeis, outras responsabilidades relativas à emissão do relatório, nome do sócio ou responsável técnico, assinatura do auditor, endereço do auditor independente e data do relatório do auditor (NBC TA 700, 2016). 


\section{Revista \\ UNEMAT de Contabilidade}

v. 10, n. 19,2021

O auditor corre o risco em emitir uma opinião de auditoria não condizente com a que de fato está apresentada pela companhia. Esses riscos estão estabelecidos na NBC TA 200 (2016) e apresentados no Quadro 2.

QUADRO 2 - Riscos de auditoria

\begin{tabular}{|l|l|}
\hline \multicolumn{2}{|c|}{ Riscos de auditoria } \\
\hline Risco de Detecção & Se os procedimentos do auditor não detectam distorções. \\
\hline Risco de Controle & O controle aplicado não foi suficiente para detectar distorções. \\
\hline Risco Inerente & $\begin{array}{l}\text { Quando a informação é frágil devido a sua suscetibilidade antes mesmo de ser } \\
\text { aplicado um controle. }\end{array}$ \\
\hline
\end{tabular}

Fonte: Elaborado pelos autores (2019)

Como meio de prevenção contra esses riscos, é estabelecido que o auditor independente juntamente com sua equipe de auditoria, deve manter sistemas de controle de qualidade para as auditorias e revisões das demonstrações contábeis para alcançar segurança razoável de que as demonstrações contábeis estão livres de distorções independentemente se causada por erro ou fraude (NBC PA 01, 2009).

Após o exame do auditor nas demonstrações contábeis, ele deve expressar de forma clara sua opinião e as evidências geradas pela auditoria. Assim, deve concluir se obteve ou não segurança razoável. Essa conclusão deve ser classificada pelos tipos de opinião modificada e não modificada (NBC TA 200, 2016).

A opinião do auditor não modificada, ou seja, sem ressalva, deve ser mencionada se o exame feito é denominado limpo, sem parágrafo adicional e as evidências são apropriadas e suficientes. Se o resultado do exame é o contrário, deve então o auditor modificar sua opinião, há três tipos de opiniões que podem ser emitidos dependendo do que levou a modificação da opinião, que são: relatório com ressalva, com opinião adversa e com abstenção de opinião (NBC TA 705, 2016). 
FLUXOGRAMA 1 - Tipos de opiniões



Fonte: Elaborado pelos autores (2019)

O auditor independente deve emitir um relatório com ressalva se obtiver evidência suficiente e apropriada, e concluir que a distorção individualmente ou em conjunto é relevante, mas, não generalizada. A opinião adversa, deve ser emitida ao concluir que as distorções individualmente ou em conjunto, são relevantes e generalizadas. Caso não seja possível obter evidências apropriadas e suficientes, o auditor deve pressupor que se fosse possível obter elas seriam generalizadas, se sim, deve abster-se de emitir sua opinião (NBA TA 705).

\subsection{TRABALHOS SIMILARES}

O Quadro 3 permite a comparação entre resultados de artigos que possuem assuntos similares, suas referências, seguido dos objetivos e resultados. 


\section{Revista \\ UNEMAT de \\ Contabilidade}

v. 10, n. 19,2021

QUADRO 3 - Trabalhos similares

\begin{tabular}{|c|c|c|}
\hline Autor(es)/Ano & Objetivos & Resultados \\
\hline Nascimento (2018) & $\begin{array}{l}\text { Identificar, analisar e comparar os } \\
\text { relatórios de auditoria independente } \\
\text { do periodo de } 2014 \text { a } 2017 \text {, para as } \\
\text { empresas listadas no segmento } \\
\text { Bovepa Mais e Novo Mercado do } \\
\text { Brasil. }\end{array}$ & $\begin{array}{l}\text { Chegou na conclusão de que das } \\
159 \text { empresas listadas, } 96,4 \% \\
\text { apresentaram relatórios } \\
\text { independentes sem ressalva. }\end{array}$ \\
\hline $\begin{array}{l}\text { Santos, Oliveira e } \\
\text { Conceição (2018) }\end{array}$ & $\begin{array}{l}\text { Analisar as características } \\
\text { dos pareceres de auditoria } \\
\text { independente emitidos sobre as } \\
\text { demonstrações contábeis das } \\
\text { empresas do setor agropecuário } \\
\text { listadas na BM\&F BOVESPA nos } \\
\text { anos de } 2010 \text { a } 2015 \text {. }\end{array}$ & $\begin{array}{l}\text { Os resultados das } 3 \text { companhias } \\
\text { indicaram que } 33,33 \% \text { dos } \\
\text { pareceres continham ressalva, } \\
\text { correspondendo, portanto, } 66,67 \% \\
\text { dos pareceres emitidos sem } \\
\text { ressalva. }\end{array}$ \\
\hline $\begin{array}{l}\text { Tisott, Peixoto, } \\
\text { Zumba, Carraro e Sousa } \\
\text { (2018) }\end{array}$ & $\begin{array}{l}\text { Analisar o relatório do } \\
\text { auditor independente das empresas do } \\
\text { ramo da construção civil referente às } \\
\text { demonstrações contábeis do exercício } \\
\text { de } 2016 \text {. }\end{array}$ & $\begin{array}{l}\text { Foram analisados } 19 \text { relatórios, } 3 \\
\text { deles com negativa de opinião, e } \\
16 \text { com opinião sem ressalva, } 98 \% \\
\text { dos relatórios analisados estão em } \\
\text { conformidade com o novo padrão } \\
\text { de relatório de auditor. }\end{array}$ \\
\hline $\begin{array}{l}\text { Patrocínio, Coutinho } \\
\text { Reina e Reina, (2017) }\end{array}$ & $\begin{array}{l}\text { Identificar os principais } \\
\text { motivos de ressalvas ou de parágrafos } \\
\text { de ênfase nos relatórios de opinião } \\
\text { dos auditores, emitidos no período de } \\
2010 \text { a } 2015 \text {, do segmento Novo } \\
\text { Mercado da BM\&FBOVESPA. }\end{array}$ & $\begin{array}{l}\text { Dos } 742 \text { relatórios } \\
\text { emitidos, apenas nove tiveram } \\
\text { abstenção de opinião, e } 12 \\
\text { apresentaram ressalvas, ou seja, } \\
\text { mais de } 97 \% \text { foram relatórios de } \\
\text { auditoria sem ressalvas. }\end{array}$ \\
\hline
\end{tabular}

Fonte: Elaborado pelos autores (2019)

Os trabalhos apresentados no Quadro 3, trataram da coleta de dados diretamente do site da B3. Além de que todos trabalharam com os relatórios de auditoria independente, de diferentes segmentos de governanças corporativas. Esta pesquisa diferencia-se por tratar não somente apenas um ramo de atividade ou uma companhia específica, mas sim um segmento (Bovespa 


\section{Revista

Tradicional), e que apresenta informações atualizadas por de um segmento original ainda não apresentado anteriormente.

\section{PROCEDIMENTOS MÉTODOLOGICOS}

Esta seção é voltada para o método aplicado e os procedimentos técnicos utilizados para o alcance do resultado, seguido da população e amostra da pesquisa e do procedimento de coleta e tratamentos de dados.

A pesquisa é caracterizada como quantitativa, e utiliza este método perante os exames das opiniões nos relatórios de auditoria, levanta os tipos de opiniões, para identificar a quantidade dos tipos de opiniões emitidas nos relatórios e para identificar qual a frequência das opiniões modificadas e não modificadas apresentada nos relatórios de auditoria.

Os procedimentos técnicos para realizar a pesquisa, são considerados como documental, devido ser utilizado como base os relatórios de auditoria publicados na B3. Para Gil (2008) a pesquisa documental é caracterizada por fazer o uso do material estudado que utiliza apenas o que for do objetivo da pesquisa.

\subsection{POPULAÇÃO E AMOSTRA}

O universo pesquisado é constituído pelas companhias praticantes da governança corporativa classificada no segmento do Bovespa Tradicional, a qual totalizam 185 companhias enquadradas como S/A, listada no site da B3.

A amostragem é formada por 179 empresas de diferentes classificações setoriais, todas listadas no segmento Bovespa Tradicional, dentre os 10 segmentos de classificação de governança corporativa existentes. Foram emitidos 185 relatórios em 2017 e 179 no ano de 2018,

por este motivo foi excluído da pesquisa as mesmas empresas que não apresentaram seus relatórios em 2018, dos resultados de 2017. O número de empresas se manteve nos dois anos. 


\section{Revista

\subsection{PROCEDIMENTOS DE COLETA E TRATAMENTO DE DADOS}

A coleta dos dados ocorreu no período entre março a junho de 2019, no sítio eletrônico da B3. Foi utilizado no acesso rápido as empresas listadas, obtido pela forma de pesquisa do segmento Bovespa Tradicional, foi acessado sequencialmente os relatórios de auditoria dos anos 2017 e 2018. Verificou-se a opinião nos relatórios, a base da opinião ao apresentar opinião modificada, o tipo de opinião e a empresa de auditoria independente transcritos para o programa Microsoft Office Excel.

\section{ANÁLISE DOS DADOS E DISCUSSÃO DOS RESULTADOS}

Esta seção trata da apresentação das razões sociais das companhias listadas no segmento Bovespa Tradicional; das companhias que não apresentaram seus relatórios em 2018; da classificação setorial; das empresas que auditaram; do levantamento dos tipos de opiniões emitidas; os motivos da modificação da opinião; e por fim, a discussão dos resultados.

As companhias listadas no Quadro 4 não publicaram suas demonstrações contábeis do ano de 2018, até o período final da coleta de dados dessa pesquisa, de modo que foram excluídas da amostra nos respectivos anos estudados. Portanto as seis companhias listadas no Quadro 4, não compõe os resultados das próximas tabelas e quadros.

QUADRO 4 - Ausência de Relatórios Publicados em 2018

\begin{tabular}{|l|}
\hline Razão Social \\
\hline Azevedo e Travassos S/A \\
\hline BRB BCO de Brasília S/A \\
\hline Inepar S/A \\
\hline Indústrias J.B. Duarte S/A \\
\hline Ouro Verde Locações \\
\hline Refinaria de Petróleo Manguinhos S/A \\
\hline
\end{tabular}

Fonte: Elaborado pelos autores (2019) 


\section{Revista

Duas das companhias que não apresentaram seus relatórios em 2018, apresentaram em 2017 seus relatórios com a opinião modificada do tipo com ressalva e uma terceira com abstenção de opinião, o restante apresentou sem ressalva.

\subsection{CLASSIFICAÇÃO SETORIAL}

A B3 classifica as companhias pelo setor de atuação do negócio, a fim de organizar e simplificar a busca pelas companhias designadas pelo ramo de atividade. A Tabela 1 apresenta a quantidade por segmento das 179 companhias examinadas.

TABELA 1- Classificação Setorial da amostra em 2019

\begin{tabular}{|lcc|}
\hline Classificação Setorial & Quantidade & Percentual \\
\hline Financeiro & 46 & $25,70 \%$ \\
\hline Utilidade Pública & 35 & $19,55 \%$ \\
\hline Bens Industriais & 32 & $17,88 \%$ \\
\hline Consumo Cíclico & 25 & $13,97 \%$ \\
\hline Materiais Básicos & 14 & $7,82 \%$ \\
\hline Consumo não cíclico & 9 & $5,03 \%$ \\
\hline Outros & 6 & $3,35 \%$ \\
\hline Saúde & 5 & $2,79 \%$ \\
\hline Telecomunicações & 3 & $1,67 \%$ \\
\hline Não classificados & 2 & $1,12 \%$ \\
\hline Petróleo & 1 & $0,56 \%$ \\
\hline Tecnologia da Informação & 1 & $0,56 \%$ \\
\hline Total & $\mathbf{1 7 9}$ & $\mathbf{1 0 0 \%}$ \\
\hline
\end{tabular}

Fonte: Elaborado pelos autores (2019)

A partir da Tabela 1, observa-se que o setor financeiro, atuante na área de intermediários financeiros, de Previdência e Seguros, exploração de imóveis e entre outros serviços, possui o maior volume de empresas listadas correspondendo à 25,70\%. As de utilidade pública responsáveis pelo fornecimento de água e saneamento, energia elétrica e gás, com 19,55\%, e em 


\section{Revista \\ UNEMAT de \\ Contabilidade}

v. 10, n. 19,2021

terceiro o setor de bens Industriais, voltada ao comércio de máquinas e equipamentos, construção pesada, engenharia e entre outros, alcança $17,88 \%$.

O menor número de empresas segmentadas são as das áreas respectivas de Tecnologia da informação $(0,56 \%)$, petróleo $(0,56 \%)$ e não classificados $(1,12 \%)$. O setor de construção civil e transporte, não possui nenhuma empresa classificada pelo segmento Bovespa Tradicional.

\subsection{EMPRESAS DE AUDITORIAS RESPONSÁVEL PELOS RELATÓRIOS}

A Tabela 2 apresenta as empresas de auditoria que emitiram relatórios nos dois anos. As empresas de auditorias e auditores independentes que emitiram menos de seis relatórios nos anos de 2017 e 2018 foram agrupadas na classificação como “outros”.

TABELA 2 - Empresas de auditoria responsável pelos relatórios em 2017 e 2018

\begin{tabular}{l|cc|cc}
\hline \multicolumn{1}{c|}{ Empresa } & \multicolumn{2}{c|}{$\mathbf{2 0 1 7}$} & Quant. & $\mathbf{2 0 1 8}$ \\
\hline KPMG & Quant. & $\mathbf{( \% )}$ & 43 & $24,02 \%$ \\
Ernest \& Young & 44 & $24,59 \%$ & 26 & $14,53 \%$ \\
PricewhaterhouseCoopers & 28 & $15,64 \%$ & 19 & $10,61 \%$ \\
BDO RCS & 20 & $11,17 \%$ & 14 & $7,82 \%$ \\
Grant Thornton & 16 & $8,94 \%$ & 13 & $7,26 \%$ \\
Delloite Touche Tohmatsu & 11 & $6,14 \%$ & 9 & $5,03 \%$ \\
BERKAN & 8 & $4,47 \%$ & 4 & $2,24 \%$ \\
Outros & 6 & $3,35 \%$ & 51 & $28,49 \%$ \\
\hline Total & 46 & $25,70 \%$ & $\mathbf{1 7 9}$ & $\mathbf{1 0 0 \%}$ \\
\hline
\end{tabular}

Fonte: Elaborado pelos autores (2019)

Verifica-se que as empresas de auditoria que mais emitiram relatórios fazem parte da chamada BIG FOUR (KPMG, Ernst \& Young, PricewaterhouseCoopers e Deloitte Touche Tohmatsu), consideradas as maiores referências dos serviços de auditoria independente (RAMALHO, 2018). O resultado comparativo entre os anos relativo ao aumento de relatórios emitidos foi da empresa Deloitte Touche Tohmatsu e Grant Thornton, não BIG FOUR. 


\section{Revista \\ UNEMAT de \\ Contabilidade}

v. 10, n. 19,2021

\subsection{OPINIÃO NOS RELATÓRIOS DAS COMPANHIAS SELECIONADAS E EMPRESAS DE AUDITORIA}

A Tabela 3 apresenta em quantidade e em percentagem os relatórios emitidos classificados pelos tipos de opiniões das 179 empresas selecionadas na B3 em 2017 e 2018. Os tipos de opiniões apresentadas com resultados maiores que zero foram sem ressalva, com ressalva e abstenção de opinião.

TABELA 3 - Tipos de opiniões emitidas em 2017 e 2018

\begin{tabular}{l|cc|cc}
\hline \multicolumn{1}{c|}{ Tipos de Opinião } & Freq. & $\mathbf{2 0 1 7}$ & \multicolumn{2}{c}{$\mathbf{2 0 1 8}$} \\
Sem Ressalva & 165 & $92,18 \%$ & 160 & $\mathbf{F r})$ \\
Com Ressalva & 10 & $5,59 \%$ & 15 & $89,38 \%$ \\
Abstenção & 4 & $2,23 \%$ & 4 & $8,39 \%$ \\
Adversa & 0 & $0,00 \%$ & 0 & $2,23 \%$ \\
\hline Total & $\mathbf{1 7 9}$ & $\mathbf{1 0 0 \%}$ & $\mathbf{1 7 9}$ & $0,00 \%$ \\
\hline
\end{tabular}

Fonte: Elaborado pelos autores (2019)

Os resultados apontam uma queda de seis relatórios denominados como limpos, ou seja, sem ressalva em 2018, que por consequência aumentaram os relatórios de opinião com ressalva de $10(5,57 \%)$ para 15 (8,39\%), um aumento de 50\% de 2017 para 2018.

Ainda, em análise aos relatórios emitidos com opinião modificada classificada como abstenção de opinião os resultados mantiveram-se em quatro (2,23\%) companhias com esta opinião, três delas repetiram este tipo de opinião nos respectivos anos, ressalta-se que nenhum relatório emitido possui a opinião adversa.

A Tabela 4 demonstra as empresas de auditoria que emitiram os relatórios por tipo de opinião modificada e não modificada nos respectivos anos, que totalizam 358 relatórios emitidos. 


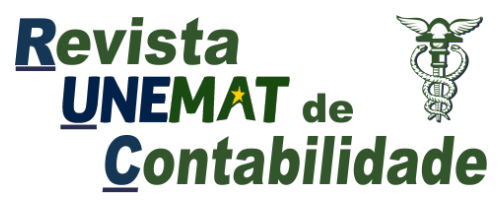

v. 10, n. 19, 2021

TABELA 4 - Empresas de auditoria e os tipos de opiniões emitidas de 2017 e 2018

\begin{tabular}{|c|c|c|c|c|c|c|c|c|}
\hline \multirow[b]{2}{*}{$\begin{array}{c}\text { Empresas de } \\
\text { auditoria }\end{array}$} & \multicolumn{4}{|c|}{2017} & \multicolumn{4}{|c|}{2018} \\
\hline & 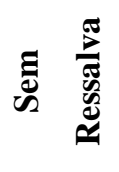 & 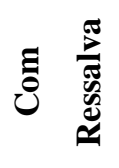 &  & $\begin{array}{l}\frac{F}{2} \\
\frac{2}{0} \\
\frac{2}{4}\end{array}$ & E & ฮี & 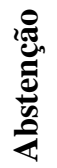 & 宽 \\
\hline KPMG & 41 & 3 & 0 & 0 & 36 & 7 & 0 & 0 \\
\hline Ernest \& Y. & 26 & 1 & 1 & 0 & 25 & 1 & 0 & 0 \\
\hline Price W. & 20 & 0 & 0 & 0 & 19 & 0 & 0 & 0 \\
\hline BDO RCS & 15 & 1 & 0 & 0 & 12 & 1 & 1 & 0 \\
\hline Deloitte T. & 7 & 1 & 0 & 0 & 7 & 2 & 0 & 0 \\
\hline Grant T. & 11 & 0 & 0 & 0 & 13 & 0 & 0 & 0 \\
\hline Berkan & 3 & 0 & 1 & 0 & 2 & 1 & 1 & 0 \\
\hline Outros & 42 & 4 & 2 & 0 & 46 & 3 & 2 & 0 \\
\hline Total & 165 & 10 & 4 & $\mathbf{0}$ & 160 & 15 & 4 & $\mathbf{0}$ \\
\hline
\end{tabular}

Fonte: Elaborado pelos autores (2019)

Devido a empresa KPMG, ter elaborado o maior número de relatórios emitidos, ela foi responsável pelo maior número de relatórios emitidos sem ressalva e com ressalva nos dois anos, seguido das empresas Ernest \& Young e de Price WaterHouse.

\subsection{MOTIVO PARA MODIFICAÇÃO DA OPINIÃO DO AUDITOR NOS RELATÓRIOS COM RESSALVA}

Apresenta-se no Quadro 5 as companhias que receberam o relatório de auditoria com a opinião como com ressalva e a empresa responsável pela auditoria em 2017 e 2018. 


\section{Revista \\ UNEMAT de \\ Contabilidade}

v. 10, n. 19, 2021

QUADRO 5 - Companhias e empresas de auditoria que emitiram a opinião com ressalva

\begin{tabular}{|c|c|c|c|}
\hline \multicolumn{2}{|l|}{2017} & \multicolumn{2}{|l|}{2018} \\
\hline Companhia & $\begin{array}{c}\text { Empresa de } \\
\text { auditoria }\end{array}$ & Companhia & $\begin{array}{c}\text { Empresa de } \\
\text { auditoria }\end{array}$ \\
\hline $\begin{array}{l}\text { Advanced Digital Health } \\
\text { Medicina Prevent. S/A }\end{array}$ & BDO RCS & $\begin{array}{c}\text { Advanced Digital Health Medicina } \\
\text { Prevent. S/A }\end{array}$ & BDO RCS \\
\hline BCO Amazônia S/A & KPMG & BCO Amazônia S/A & KPMG \\
\hline Bradesco LSG & KPMG & Bradesco LSG & KPMG \\
\hline $\begin{array}{c}\text { BC Leasing - Arrendamento } \\
\text { Mercantil S/A }\end{array}$ & KPMG & $\begin{array}{c}\text { BC Leasing - Arrendamento } \\
\text { Mercantil S/A }\end{array}$ & KPMG \\
\hline Bombril S/A & Ernest \& Y. & Celulose Irani S/A & KPMG \\
\hline Celulose Irani S/A & Deloitte T. & Cia Celg. de Participações Celgpar & BERKAN \\
\hline Metalgráfica Iguaçu S/A & Outros & $\begin{array}{l}\text { Conc.Sist. Anhang - Bandeirant. } \\
\text { S/A }\end{array}$ & KPMG \\
\hline Nordon Indústrias Metalúrgicas & Outros & Conc. Rod. Oeste SP Viaoeste S/A & KPMG \\
\hline Tecnosolo Engenharia S/A & Outros & Cia Tecidos Santanense & Deloitte T. \\
\hline Wetzel S/A & Outros & $\begin{array}{c}\text { Ecorodovias Concessões e Serviços } \\
\text { S/A }\end{array}$ & Deloitte T. \\
\hline & & $\begin{array}{c}\text { Empresa Conc. Rodov. do Norte } \\
\text { S/A }\end{array}$ & Ernest \& Y. \\
\hline & & Ferrovia Centro Atlânt. S/A & KPMG \\
\hline & & Metalgráfica Iguaçu S/A & Outros \\
\hline & & Nordon Ind. Metalúrgicas & Outros \\
\hline & & Tecnosolo Engenharia S/A & Outros \\
\hline
\end{tabular}

Fonte: Elaborado pelos autores (2019)

Observa-se que sete companhias permaneceram em ambos os anos com a opinião em seu relatório com ressalva, e apenas a companhia Celulose Irani S/A mudou de empresa de auditoria na troca dos anos.

O Quadro 6, apresenta os motivos que levaram aos auditores emitirem os relatórios com ressalva. Nota-se a duplicidade de motivos de 2017 para 2018. Isso ocorre devido a opinião com ressalva persistirem em algumas companhias ano após ano. 
QUADRO 6- Motivos das opiniões com ressalva

\begin{tabular}{|c|c|c|}
\hline Ano & Freq. & Motivos \\
\hline \multirow{6}{*}{2017} & 8 & Aguardo de resultados de fatores externos ou de processos judiciais \\
\hline & 4 & Incerteza relevante relacionada com a continuidade operacional \\
\hline & 4 & Método inadequado de práticas contábeis \\
\hline & 2 & Indisponibilidade da totalidade de documentos ou informações \\
\hline & 1 & Diferença não conciliada \\
\hline & 1 & Falta de atualização de saldo \\
\hline \multirow{9}{*}{2018} & 6 & Método inadequado de práticas contábeis \\
\hline & 4 & Incerteza relevante relacionada com a continuidade operacional \\
\hline & 3 & Aguardo de resultados de fatores externos ou de processos judiciais \\
\hline & 3 & $\begin{array}{l}\text { Impossibilidade de apresentar a totalidade da documentação suporte, por } \\
\text { abrangerem fatos e informações protegidas por segredo de justiça. Acusada por } \\
\text { meio de delações premiadas e/ou existência de provas de práticas de crimes de } \\
\text { corrupção ativa e passiva, lavagem de dinheiro, fraude licitatória, peculato e } \\
\text { associação criminosa. }\end{array}$ \\
\hline & 1 & $\begin{array}{l}\text { Ausência de Informação e de auditoria da parte de empresas investidas e } \\
\text { controladas }\end{array}$ \\
\hline & 1 & $\begin{array}{l}\text { Investigações pelo Ministério Público Federal e determinadas denúncias que } \\
\text { envolvem duas controladas da Companhia }\end{array}$ \\
\hline & 1 & Diferença não conciliada \\
\hline & 1 & Falta de atualização de saldo \\
\hline & 1 & Indisponibilidade da totalidade de documentos ou informações \\
\hline
\end{tabular}

Fonte: Elaborado pelos autores (2019) 


\section{Revista

O ano de 2018 apresentam novos motivos que estão ligados às investigações originadas por delação premiada das companhias Conc. Sist. Anhang - Bandeirant S/A, Empresa Conc. Rodov. do Norte S/A e Conc. Rod. Oeste SP Viaoeste S/A da própria companhia ou de suas companhias investidas e controladas enquadradas em outros segmentos de governança corporativa.

Os registros contábeis das companhias delatadas ficam protegidos por segredo da justiça e impedem que o auditor tenha evidência suficiente para emitir sua opinião sem ressalva. As delações premiadas decorrentes da maior operação de investigação de corrupção e lavagem de dinheiro do Brasil, a operação Lava Jato desenvolvido desde 2014 (MPF, 2019).

\subsection{MOTIVO PARA ABSTENÇÃO DA OPINIÃO DO AUDITOR NOS RELATÓRIOS DE AUDITORIA}

A abstenção de opinião deve ocorrer se o auditor não possui evidência suficiente para emitir sua opinião, e que se fosse possível obter, a distorção seria de forma generalizada, ou seja, afetaria todas as demonstrações contábeis. (NBC TA 705, 2016). O Quadro 7 representa as companhias que receberam seus relatórios com abstenção de opinião e as empresas de auditoria responsáveis pela opinião.

QUADRO 7 - Companhias e empresas de auditoria que emitiram abstenção de opinião

\begin{tabular}{|c|c|c|c|}
\hline \multicolumn{2}{|c|}{2017} & \multicolumn{2}{c|}{2018} \\
Companhia & $\begin{array}{c}\text { Empresa de } \\
\text { auditoria }\end{array}$ & Companhia & auditoria \\
\hline IGB Eletrônica S/A & Outros & IGB Eletrônica S/A & Outros \\
\hline Mendes Junior Engenharia & Outros & Libra Terminal Rio S/A & BDO RCS \\
\hline PDG Companhia Securitizadora & Ernest \& Y. & PDG Companhia Securitizadora & Outros \\
\hline Teka - Tecelagem Kuehnrich S/A & BERKAN & Teka - Tecelagem Kuehnrich S/A & BERKAN \\
\hline
\end{tabular}

Fonte: Elaborado pelos autores (2019)

Analisa-se que três companhias receberam a mesma opinião nos dois anos, e que a companhia PDG Companhia Securitizadora trocou de empresa de auditora entre os anos. 


\section{Revista

O Quadro 8 apresenta os motivos para abstenções de opiniões nos relatórios de auditoria dos anos 2017 e 2018.

QUADRO 8 - Motivos da abstenção de opinião

\begin{tabular}{|c|c|c|}
\hline Ano & Freq. & Motivos \\
\hline \multirow{6}{*}{2017} & 6 & Incerteza quanto à origem de valores e/ou levantamento de valores. \\
\hline & 3 & $\begin{array}{l}\text { Recuperação judicial em andamento sofrendo necessidades de ajustes } \\
\text { após seu resultado. }\end{array}$ \\
\hline & 2 & Incerteza relevante relacionada com a continuidade operacional. \\
\hline & 1 & Fraquezas relevantes nos controles internos \\
\hline & 1 & Limitação do trabalho de auditoria. \\
\hline & 1 & Não foi possível concluir a continuidade operacional. \\
\hline \multirow{7}{*}{2018} & 5 & Incerteza quanto à origem de valores e levantamento de valores. \\
\hline & 3 & $\begin{array}{l}\text { Recuperação judicial em andamento sofrendo necessidades de ajustes } \\
\text { após seu resultado }\end{array}$ \\
\hline & 3 & Incerteza relevante relacionada com a continuidade operacional. \\
\hline & 1 & Fraquezas relevantes nos controles internos. \\
\hline & 1 & Limitação do trabalho de auditoria. \\
\hline & 1 & $\begin{array}{l}\text { Plano de recuperação judicial aprovado, podendo sobre alterações em seu } \\
\text { valor por falta de inclusão de credores. }\end{array}$ \\
\hline & 1 & Não foi possível concluir a continuidade operacional \\
\hline
\end{tabular}

Fonte: Elaborado pelos autores (2019)

Nota-se que alguns motivos se repetem entre os anos, exceto pelos dois últimos motivos apresentados no Quadro 11 no ano de 2018.

Em relação ao motivo de companhias que estão em recuperação judicial é possível que no ano de 2017 a companhia ainda estava com seu plano de recuperação judicial em andamento e 


\section{Revista \\ UNEMAT de Contabilidade}

v. 10, n. 19,2021

em 2018 foi aprovado, mas, será necessário sofrer alterações, valores que são essenciais para elaborar as demonstrações contábeis. Outro motivo que também é relacionado à recuperação judicial que está em andamento ocorre devido não ser possível mensurar os efeitos do plano de recuperação sobre as demonstrações financeiras.

\subsection{DISCUSSÃO DOS RESULTADOS}

Os resultados apresentados demonstram que das 185 empresas listadas no segmento Bovespa Tradicional, todas apresentaram seus relatórios de auditoria em 2017 e 179 no ano de 2018 até o período fim desta pesquisa. Devido este fato, foram excluído seis empresas da pesquisa no ano de 2017. Os resultados apontaram que o setor financeiro lidera na classificação setorial enquanto o setor da tecnologia da informação e de petróleo são o menos representativos neste segmento.

A análise sobre as opiniões demonstram que as opiniões modificadas cresceram em 2018, apesar de seis empresas não apresentarem seus relatórios até a data fim desta pesquisa.

Verifica-se o aumento de opiniões modificadas (com ressalva e abstenção de opinião) em 2018, em 3,05\%. Em contrapartida, há diminuição dos relatórios emitidos sem ressalva. Ressaltase que nestes períodos não foi emitido relatório com opinião adversa. Os motivos para a modificação da opinião geralmente se repetem entre os anos das mesmas companhias, exceto pelo ano de 2018 que apresentou motivos novos relacionados às investigações da operação Lava Jato.

\section{CONSIDERAÇÕES FINAIS}

O objetivo desta pesquisa foi verificar as opiniões emitidas nos relatórios de auditores independentes dos anos de 2017 e 2018, essenciais para os negócios na bolsa de valores, de companhias listadas na B3.

Essas companhias estão classificadas pelo segmento Bovespa Tradicional, um setor que segue uma governança corporativa de regras apenas exigidas pela lei, não enquadrado pela B3 como um nível diferenciado, que identifica os tipos de opinião (se modificada ou não modificada). 


\section{Revista \\ UNEMAT de Contabilidade}

v. 10, n. 19, 2021

O trabalho está limitado às companhias segmentadas no Bovespa Tradicional. As sugestões para os próximos estudos são de realizar a pesquisa das companhias que não apresentaram seus relatórios em 2018, a fim de completar a pesquisa e realizar comparações destes resultados com outros segmentos da B3.

Após a busca dos relatórios de auditoria dessas empresas, das 185 empresas listadas, seis não apresentaram seu relatório de auditoria exercício 2019, ano base 2018, até junho de 2019, por este motivo elas não fizeram parte da análise e resultados da pesquisa.

Foi feito o exame dos documentos e observou-se que as empresas que mais participam de auditoria no Brasil, fazem parte do grupo Big Four. Percebeu-se com a classificação setorial, que há diversos setores ligados a este segmento, liderado pelo setor financeiro (instituições bancárias, seguros e holdings).

Em 2017, os resultados apontaram que 7,26\% das companhias receberam seus relatórios com opinião modificada e em 2018, o número cresceu para 10,61\%. É válido confirmar que o trabalho do auditor está cada mais em destaque por transmitir informações relevantes aos seus usuários. Ressalta-se que em 2018 os motivos permeiam devido investigações relacionadas às práticas de crimes de corrupção ativa e passiva, lavagem de dinheiro, fraude licitatória, peculato e associação criminosa. Reforça que o trabalho do auditor independente proporciona transparência para a sociedade e aos usuários das informações.

\section{REFERÊNCIAS}

ALMEIDA, Marcelo Cavalcanti. Auditoria: um curso moderno e completo. 8. ed. São Paulo: Atlas S.A., 2012.

BRASIL. Resolução CFC 2016/NBCTA200(R1), de 05 de setembro de 2016. Altera a NBC TA 200 que dispõe sobre os objetivos gerais do auditor independente e a condução da auditoria em conformidade com normas de auditoria. Diário Oficial da União, Brasília, DF, 09 de set. 2016. Disponível em: http://cfc.org.br/tecnica/normas-brasileiras-de-contabilidade/nbc-ta-de-auditoriaindependente/.Acesso em: 02 jun. 2019. 


\section{Revista \\ UNEMAT de \\ Contabilidade}

v. 10, n. 19,2021

BRASIL. Casa Civil. Lei $n^{\circ}$ 6.404, DE 15 DE DEZEMBRO DE 1976. Dispõe sobre as Sociedades por Ações. Diário Oficial da União, Brasília, DF, 15 dez. 1976.Disponível em: http://www.planalto.gov.br/ccivil_03/leis/L6404consol.htm. Acesso em:06 jun. 2019.

BRASIL. Casa Civil. Lei no 6.385, DE 07 DE DEZEMBRO DE 1976. Dispõe sobre o mercado de valores mobiliários e cria a Comissão de Valores Mobiliários. Diário Oficial da União, Brasília, DF, 09 dez. 1976. Disponível em: http://www.planalto.gov.br/ccivil_03/leis/16385.htm. Acesso em: 06 maio 2019.

BRASIL. Resolução CRC n ${ }^{\circ} 1.201 / 09$ de 27 de Novembro de 2009. Aprova a NBC PA 01 Controle de Qualidade para firmas (Pessoas Jurídicas e Físicas) de Auditores Independentes. Ata CFC n ${ }^{\circ}$ 931, Brasília, DF, 27 de nov. 2009. Disponível em: http://www1.cfc.org.br/sisweb/sre/detalhes_sre.aspx?Codigo=2009/001201. Acesso em: 06 Jun. 2019.

BRASIL, Comissão de Valores Mobiliários (CVM). Instrução CVM nº 308 de 14 maio de 1999. Dispõe sobre o registro e o exercício da atividade de auditoria independente no âmbito do mercado de valores mobiliários, define os deveres e as responsabilidades dos administradores das entidades auditadas no relacionamento com os auditores independentes.Diário Oficial da União,

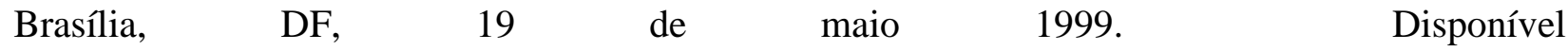
em:http://www.cvm.gov.br/legislacao/instrucoes/inst308.html. Acesso em: 27 Abr. 2019.

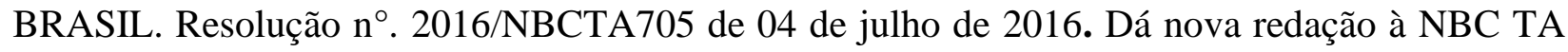
705 que dispõe sobre modificações na opinião do auditor independente. Diário Oficial da União, Brasília, DF, 04 dez. 2009 Disponível em: http://www2.cfc.org.br/sisweb/sre/detalhes_sre.aspx?Codigo=2016/NBCTA705. Acesso em: 27 Abr. 2019.

BRASIL. Resolução CFC n. . 2016/NBCTA700 de 04 de julho de 2016. Dá nova redação à NBC TA 700 que dispõe sobre a formação da opinião e emissão do relatório do auditor independente sobre as demonstrações contábeis. Diário Oficial da União, Brasília, DF, 04 de dez. 


\section{Revista

2009.Disponível

em:

http://www2.cfc.org.br/sisweb/sre/detalhes_sre.aspx?Codigo=2016/NBCTA700. Acesso em: 27 Abr. 2019.

BRASIL, Bolsa Balcão. Institucional. São Paulo: B3, (2019). Disponível em: http://www.b3.com.br/pt_br/b3/institucional/controles-internos-e-riscos-corporativos/. Acesso em: 06 Maio 2019.

BRASIL, Bolsa Balcão. Segmentos de listagem.São Paulo: B3, (2019). Disponível em: http://www.b3.com.br/pt_br/produtos-e-servicos/solucoes-para-emissores/segmentos-delistagem/sobre-segmentos-de-listagem/. Acesso em: 02 Jun. 2019.

BRASIL, Ministério Público Federal. Entenda o caso. Brasília, SF, 2019. Disponível em: http://www.mpf.mp.br/grandes-casos/caso-lava-jato/entenda-o-caso. Acesso em: 06 jun 2019.

CONSELHO REGIONAL DE CONTABILIDADE DO CEARÁ, Auditoria Contábil: Origem da auditoria Contábil. Ceará, 2019. Disponível em: http://www.crcce.org.br/fiscalizacao/informacoes-importantes/auditoria-contabil/. Acesso em: 02 Jun. 2019.

COMISSÃO DE VALORES MOBILIÁRIOS. Auditores Independentes. Brasília, DF, 2019. Disponível em:http://www.cvm.gov.br/menu/regulados/auditores_independentes/sobre.html. Acesso em: 31 maio 2019.

COMISSÃO DE VALORES MOBILIÁRIOS. Sobre a CVM. Brasília, DF, 2019. Disponível em:http://www.cvm.gov.br/menu/acesso_informacao/institucional/sobre/cvm.html. Acesso em: 02 jun. 2019.

COMISSÃO DE VALORES MOBILIÁRIOS. Instrução CVM 586. Brasília, DF, 2019. Disponível em: http://www.cvm.gov.br/legislacao/instrucoes/inst586.html Acesso em: 02 jun. 2019. 


\section{Revista

de Assis, E. T., de Oliveira Alvarenga, F., \& Lacerda, C. F. J. (2014). Relevância e Desafios do Perfil do Auditor Externo: um Estudo de Caso. SEGeT 2014 XI Simpósio de Excelência em

Gestão e Tecnológica, 2014. Disponível em: https://www.aedb.br/seget/arquivos/artigos14/702050.pdf. Acesso em: 06 jun. 2019.

GIL, A. C. Métodos e técnicas de pesquisa social. 6.ed. São Paulo: Atlas, 2008.

Instituto Brasileiro de Governança Corporativa (IBGC), Princípios que geram valor de longo prazo. Disponível em: https://www.ibgc.org.br/quemsomos. Acesso em: 06 Maio 2019.

Instituto Brasileiro de Governança Corporativa (IBGC), Referência em Governança Corporativa. Disponível em: https://www.ibgc.org.br/conhecimento/governanca-corporativa. Acesso em: 06 Maio 2019.

NASCIMENTO, Matelson Nunes do. Uma análise nos relatórios de auditoria independente das empresas do Bovespa mais e novo mercado do ano de 2014 a 2017. 2018. TCC (Graduação em Ciências Contábeis) - Universidade Estadual da Paraíba, Monteiro, 2018. Disponível em: http://dspace.bc.uepb.edu.br/jspui/handle/123456789/16859. Acesso em: 02 abr. 2019.

RAMALHO, Mariana Ramos. A qualidade da auditoria: as Big Four. 2018. Dissertação (Mestrado apresentado ao Instituto de Contabilidade e Administração) - Instituto Superior de Contabilidade e Administração do Porto, Porto, 2018. Disponível em: http://recipp.ipp.pt/handle/10400.22/12567. Acesso em: 02 abr. 2019.

SANT'ANNA, Francisco. Orgulho de ser auditor independente, 2018. Disponível no link http://www.ibracon.com.br/ibracon/Portugues/detArtigo.php?cod=37 Acesso em: 27 abr. 2019. 